\title{
METROLOGY FOR INTRAOCULAR PRESSURE MEASUREMENTS
}

\author{
D. Pražák ${ }^{1}$, R. Ziółkowski², D. Rosu ${ }^{3}$, M. Schiebl ${ }^{4}$, J. Rybář ${ }^{5}$, P. Pavlásek ${ }^{5,6}$, E. Sınır ${ }^{7}$, F. Pluháček ${ }^{8}$ \\ ${ }^{1}$ ČMI, Brno, Czechia, dprazak@cmi.cz \\ ${ }^{2}$ GUM, Warszawa, Poland, robert.ziolkowski@gum.gov.pl \\ ${ }^{3}$ PTB, Berlin, Germany, dana.rosu@ptb.de \\ ${ }^{4}$ PTP-BEV, Wien, Austria, markus.schiebl@bev.gv.at \\ ${ }^{5}$ Slovak University of Technology, Bratislava, Slovakia, jan.rybar@stuba.sk \\ ${ }^{6}$ SMÚ, Bratislava, Slovakia, pavlasek@smu.gov.sk \\ 7 TÜBİTAK UME, Kocaeli, Turkey, ekrem.sinir@tubitak.gov.tr \\ ${ }^{8}$ Palacký University Olomouc, Olomouc, Czechia, frantisek.pluhacek@upol.cz
}

\begin{abstract}
:
The World Health Organization reports glaucoma as the second leading cause of blindness and the leading cause of irreversible blindness. Intraocular hypertension is the most relevant and only treatable risk factor for the disease. Non-invasive intraocular-pressure (IOP) measurements, carried out using eye tonometers, are used to screen for the intraocular hypertension. A correct measurement of the IOP is essential in the prevention and the fight against glaucoma. The authors present their work towards ensuring on one side the accuracy of IOP measurements for contact and non-contact tonometers in the Central European region and obtaining a harmonization of the requirements for IOP metrology at national level.
\end{abstract}

Keywords: eye tonometer; intraocular pressure; medical metrology; metrological traceability

\section{INTRODUCTION}

In addition to the European regulations for the medical devices with a measuring function entering the market, some European countries (e.g. Czech Republic and Germany) have their own national regulations to ensure the proper performance of the eye-tonometers in operation. These are implemented through the periodic metrological checks performed by national metrology institutes (NMIs) and private or governmental verification offices. However, most European NMIs are not able to ensure a correct metrological traceability in this field.

To overcome this, the project "Developing research capabilities for traceable intraocular pressure measurements" (inTENSE) was jointly initiated by the NMIs of Austria (PTP-BEV), Czech Republic (ČMI), Germany (PTB), Poland (GUM), Slovakia (SMÚ) and Turkey (TÜBİTAK UME), together with Palacký University in Olomouc
(UPOL) and Slovak Technical University in Bratislava (STU) within the framework of the European Metrology Programme for Innovation and Research (EMPIR).

\section{PROJECT OBJECTIVES}

\subsection{Competence centre}

One of the project's aims was to establish a competence centre for the IOP metrology at the location of ČMI that would not only benefit Czech costumers, but other European NMIs and stakeholders as well. This required the establishment of the necessary research capabilities for the IOP measurements in the physiological and pathophysiological range of $10 \mathrm{mmHg}-80 \mathrm{mmHg}$ $(1.333 \mathrm{kPa}-10.67 \mathrm{kPa})$ at the $\breve{C} \mathrm{MI}$.

\subsection{Emerging techniques}

Another objective of the project (and of the competence centre after the end of the project) was further development of these capabilities and keeping the pace with the technological progress in this field. The currently existing state-of-the-art in the IOP metrology would be further advanced to emerging ophthalmological measurands (which can be additionally determined using the modern eye tonometers, such as e.g. corneal thickness) and to the IOP measurements under non-standard conditions (e.g. incumbent patients). The external scientific expertise from university partners was crucial to achieve this goal, therefore the strong cooperation between NMIs and universities initiated within the project will continue during the existence of the centre.

\subsection{Extending the centre}

On a mid to long term basis, the competence centre would make its expertise in the IOP metrology accessible to a broad range of countries. This will be achieved by expanding the Smart 
Specialisation Concept (SSC), geographically beyond Central Europe and thematically towards other relevant quantities in the area of the medical device metrology.

\section{PROJECT RESULTS}

\subsection{Competence centre}

At the beginning of the project, PTB was the only NMI able to provide the state-of-the-art in the field of IOP metrology. This expertise was transferred during the project to ČMI and represented a critical step in the impending establishment of the competent centre for IOP metrology.

All the planned advanced trainings of the ČMI personnel by the experts of the PTB were successfully accomplished and the needed technical expertise was gained. The efficacy of these trainings was assessed and confirmed by two external experts in November 2018. In addition, a rigorous quality control system was established at CMI for all procedures related to the IOP measurements. An external audit of the tonometry related sections of the quality system of CMI was successfully completed in March 2020. This ensures the qualification of the traceable measurement and research capabilities jointly developed at CMI for the IOP measurements using common tonometer types in the physiological and pathophysiological range of $10-80 \mathrm{mmHg}$.

Consequently, the foundation of the competence centre in IOP metrology was laid and clear steps in the establishment of this centre were taken. An important part was a bilateral comparison in the IOP between CMI and STU. The laboratory standards involved were two clinically tested non-contact (airpuff) eye tonometers and both the set of the silicone eyes and an artificial model eye served as the transfer standard. The report of this successful comparison is available at the project's website [1].

The centre also offered the first trainings to the project partners and stakeholders. The first of these trainings took place in the mid of March 2020, but the series was then interrupted due to outbreak of covid-19 epidemic. These trainings will be resumed after the travel restrictions will be lifted. The Best Practice Guidelines developed during the project can also be found at [1]. Moreover, the consortium prepared a draft of a new OIML international recommendation on "Ophthalmic instruments Non-contact tonometers." It is in the process of being approved and after that it will complement the existing OIML R 145 "Ophthalmic instruments Impression and applanation tonometers."

\subsection{Emerging techniques}

This part was started with a thorough literature search. Firstly, the factors that significantly influence the IOP measurements in the standard and non-standard conditions and for the most widely used eye-tonometers were identified. In general, it was found that the IOP readings are mostly affected by corneal thickness and biometrical properties such as hysteresis and corneal rigidity. Secondly, the effects of different parameters (including the nonstandard measurement conditions) on the IOP measurements and uncertainties were summarized. Especially the short-term physiological stress factors on the IOP were studied. It was found that such factors can affect the IOP values immediately before the measurement and significantly distort the results. Both final reports concerning these findings are also available at [1]. Clinical studies focused on the influence of hypoxia, head and body position on the IOP values were performed and the results of these studies were published [2-3]. From a clinical view, the most important seems to be change of position and short-term physical activity, which induce immediate clinically significant (i.e. > $2 \mathrm{mmHg}$ ) IOP changes. It also seems, that supine position corresponds with higher IOP readings. Other effects such as short-term hypoxia or maximal activity cause clinically insignificant mean changes of IOP, although individual fluctuations may exceed the safe range and may be a risk factor especially for glaucoma patients. The incidence of discussed parameters is limited to a small time interval after their termination, usually within 20 min. Based on these results, it can be recommended to keep at least $20 \mathrm{~min}$ rest before the IOP measurement. The final reports [1] also present that coffee and energy drinks as well as water intake can change IOP. Thus, the measured subjects should avoid drinking of coffee or energy drinks in day of measurement or higher amount of water at least one hour before the measurement.

A virtual digital model of the eye cornea was created at STU. Then a real mechanical model (artificial eye) corresponding to the virtual model was constructed for the experimental verifications [4-9]. STU used this artificial eye as one of the transfer-standards in the mentioned above eyetonometry comparison. In a separate study, UPOL collected and evaluated the IOP data using rebound and non-contact tonometers accompanied with the respective cornea properties data [10]. According to the previous literature review, the results indicate that the measurement of intraocular pressure using rebound and non-contact tonometers is influenced by corneal hysteresis and corneal thickness. This observation may also indirectly reflect the effect of corneal rigidity, which is correlated with the thickness. If some of these parameters are markedly out of the normal range, the IOP reading can be distorted. Moreover, corneal hysteresis significantly influences mutual differences between both 
measurement techniques. Thus, the measurement of corneal thickness, hysteresis or rigidity together with intraocular pressure could help to judge the clinical validity of IOP readings.

\subsection{Extending the centre}

One important aspect for the establishment, functioning and broadening of the competence centre was the investigation and full understanding of the EU and the relevant national legislations [11]. The consortium evaluated the content of the Medical Devices Regulation and discussed it during a workshop in Berlin in October 2019 (some presentations are available at [12]). A workshop focused on the SSC was organised by GUM in Warszawa in August 2019 (some presentations are available at [1]). In addition, the consortium openly addressed the impact of the changes introduced by the New SI to the medical and metrological communities [13].

All these findings and the feed-back obtained during the discussions at the mentioned above workshops were incorporated into "White Paper on the smart specialisation concept developed to ensure a coordinated and optimised Central European approach towards IOP metrology" [1]. This document summarizes the principles of the IOP metrology SSC and the commitments of the competence centre at ČMI.

From the beginning it was envisaged that the SSC would be extended in future geographically beyond the Central Europe and thematically beyond the IOP metrology. The first step towards broadening the cooperation network established for the field of IOP metrology within the SSC, was taken by adding blood pressure instruments to the priority list of the competence centre and geographically expanding it to other European countries (Portugal, Slovenia, Ireland and Bosnia and Herzegovina) [14]. Based on the all mentioned above experiences, "Strategic plan for a panEuropean centre on medical device metrology was sketched and can be found at [1].

\section{SUMMARY AND OUTLOOK}

The competence and training centre for IOP metrology at ČMI, established within the project, will continue providing services after the end of the project. These services will be permanently improved and upgraded according to the advancement of the technology and will ensure and maintain an up-to-date IOP-metrology infrastructure for all interested European NMIs and international stakeholders.

The real mechanical eye model, prepared within the project, will be used for practical simulation of influence of different corneal factors to verify and specify their relationship with IOP reading. Based on the final reports summarising effects of corneal factors as well as physiological stress factors on IOP, the new studies are planned. The obtained data and findings will also be published to share with professional public.

\section{ACKNOWLEDGEMENT}

This work was funded through the European Metrology programme of Innovation and Research (EMPIR) Project 16RPT03 inTENSE. The EMPIR initiative is cofounded by EU Horizon 2020 programme and the EMPIR Participating States.

\section{REFERENCES}

[1] http://intense.cmi.cz

[2] E. Najmanová, F. Pluháček, M. Botek, J. Krejčí, J. Jarošová "Intraocular Pressure Response to ShortTerm Extreme Normobaric Hypoxia Exposure", Frontiers in Endocrinology, 2019.

doi: https://doi.org/10.3389/fendo.2018.00785

[3] E. Najmanová, F. Pluháček, M. Haklová "Intraocular pressure response affected by changing of sitting and supine positions", Acta Ophthalmologica, 2019. doi: https://doi.org/10.1111/aos.14267

[4] J. Rybář, M. Chytil, S. Ďuriš, B. Hučko, F. Maukš, P. Pavlásek, "Use of suitable materials such as artificial cornea on eye model for calibration of optical tonometers", AIP Conference Proceedings, vol. 2029, 020067, 2018.

doi: https://doi.org/10.1063/1.5066529

[5] P. Pavlásek, et al. "Development of New Calibration Standard for Noncontact Tonometers", in Proc. of $11^{\text {th }}$ CISP-BMEI 2018 Beijing. doi: https://doi.org/10.1109/CISP-BMEI.2018.8633148

[6] B. Hučko, S. L. Ferková, S. Ďuriš, J. Rybář, P. Pavlásek, "Glaucoma vs. biomechanical properties of cornea", Strojnícky časopis - Journal of Mechanical Engineering, Vol. 69, No. 2, pp. 111116, 2019.

doi: https://doi.org/10.2478/scjme-20190021

[7] P. Pavlásek, J. Rybář, M. Chytil, S. Ďuriš, J. Palenčár, B. Hučko, "European project on developing research capabilities for traceable intraocular pressure measurements", Zdravotníctvo a sociálna práca - Health and Social Work, Vol. 14, No. 1, pp. 30-36, 2019.

http://zdravotnictvoasocialnapraca.sk/wpcontent/uploads/ZaSP_Cislo_1_2019_SK.pdf

[8] P. Pavlásek, et al. "Developments in non-contact eye tonometer calibration", in Proc. of IEEE I2MTC 2019 Auckland. doi: https://doi.org/10.1109/I2MTC.2019.8827028

[9] B. Hučko, L. Kučera, S. Ďuriš, P. Pavlásek, J. Rybář, J. Hodál, "Modelling of cornea applanation when measuring eye pressure", Lecture Notes in Mechanical Engineering, pp. 287-294, 2020. doi: https://doi.org/10.1007/978-3-030-33146-7_33

[10] F. Pluháček, A. Unzeitigová, K. Marešová, J. Rybár, "The influence of the cornea on intraocular pressure measurement by ICARE PRO and ORA", Czech and Slovak Ophtalmology, Vol. 75, No. 3, 
pp. 111-118, 2019.

doi: https://doi.org/10.31348/2019/3/1

[11] E. Sinır, et al. "Towards the Harmonization of Medical Metrology Traceability in Europe: An Impact Case Study through Activities in Turkey and EMPIR Project inTENSE", in Proc. of IEEE MeMeA 2019 Conference Istanbul. doi: https://doi.org/10.1109/MeMeA.2019.8802141
[12] https://medmet2019.ptb.de

[13] D. Pražák, V. Sedlák, E. Sınır, F. Pluháček "Changing the status of $\mathrm{mmHg}$ ", Accreditation and Quality Assurance, 2019. doi: https://doi.org/10.1007/s00769-019-01414-7

[14] https://www.adossig-empir.eu 